\title{
選点法による回転壳の応力波伝播問題の解析 \\ APPLICATION OF THE COLLOCATION METHOD TO STRESS WAVE PROBLEMS OF SHELLS OF REVOLUTION
}

\author{
三上 隆*・芳村 仁**
}

By Takashi MIKAMI and Jin YOSHIMURA

\begin{abstract}
The collocation method for wave propagation problems of elastic shells of revolution is developed. This is a weighted residual method in which the collocation points are taken at the roots of orthogonal polynomial.

In this paper the collocation method is employed to replace a partial differential equations by a system of ordinary differential equations in time, and the resulting equations are solved by two different numerical methods of time integration : an implicit (Houbolt) method and an explicit (second order central difference) method.

The versatility and accuracy is illustrated through several numerical examples. The method appears to be relatively easy to formulate and gives satisfactory results.

Keywords : collocation method, shells of revolution, stress wave problems
\end{abstract}

\section{1. まえがき}

構造物の動的問題は，構造の全体的振動を扱い，低次 の振動モードに支配される構造振動問題と局所的な波の 伝播を追跡し，低次のみならず高次モードにも支配され る波動伝播問題に大別される.

本論文は後者の問題を対象とし, 時間領域には直接積 分法の使用を前提とした空間領域の一離散化手法を提示 するとともに, 具体的な数值計算例によって, その有効 性や妥当性の検証を行ったものである.

回転殼の動的応答問題の場合, 解析解が得られるのは それほど多くはなく,一般には近似的手法が適用される. その際とられる過程は，まず数值解析手法 (FDM, FEMなど $)^{11}$ により空間を近似することである. しかし ながら,これらの手法を波動伝播の間題に適用すれば, 要求される精度に呼応して, 構造振動問題に適用すると き以上の格子点数や要素分割数が必要となり, 大次元な 行列の演算の必要性や計算精度の低下などの固有の問題 が生じる.

本論文は，以上の状況を踏まえ，回転款の応力波伝播

* 正会員 工修 北海道大学助手 工学部土木工学科 （テ060 札幌市北区北 13 西 8)

** 正会員 工博 北海道大学教授 工学部土木工学科(同上)
の問題を扱う際の一計算法として, 選点法による実用的 解法を述べたものである.ここで提示する手法は, 古典 殻理論に基づき構造振動問題を扱った前論文 ${ }^{2)}$ を基礎と するが, 計算対象とする問題の固有の特性およびそれに 起因する数值解析上の問題点に考慮を払い, 拡張整理し たものである.すなわち，(1)応力波伝播の問題において， 重要な因子となるせん断変形と回転慣性の影響8 101 ) が考 慮された修正殸理論に基づく定式化を行った. (2)選点法 に基づいて定式化された時間に関する 2 階の連立常微分 方程式に対し，陽 (explicit) と陰 (implicit) の直接時 間積分法を適用して構成した, 2 種の解析アルゴリズム を提示した. 各アルゴリズムは, 選点法固有の利点が生 かされて次数の低い行列演算により解が得られるものと なっており, 選点法と陽解法の組合せに対しては必然的 に，また選点法と陰解法の組合せに対しては，FEM で 知られている部分構造法に類似な手法の導入により可能 となったものである. (3)陽解法による場合, 時間間隔に 関する安定限界と選点法に基づいて定式化された固有振 動問題の関連を明確にした.

数値計算例では，まず解析解が容易に得られる円筒壳 について行い, 解の比較を通して本手法の有効性, 妥当 性について検討を加えた後, 任意形状の回転殻への一適 用例として，双曲殼の解析例を示す. 


\section{2. 基礎方程式}

修正殼理論に基づく基礎式の誘導過程は，文献 3）に 譲ることにして，ここでは後の展開で必要なことのみを 示す、なお，款は等方等質な一様な厚さとした。

Fig. 1 に示すように, 経線, 円周方向座標を $(x, \theta)$, 法線方向座標 $z$ を垂直外向きに定める. 座標 $(x, \theta, z)$ に対応する変位成分を $(U, V, W),(x, \theta)$ 軸に垂直な 断面の回転角成分を $\left(\Phi_{x}, \Phi_{\theta}\right)$ とする. また, 荷重, 合 応力および合モーメントの成分を $\left(P_{x}, P_{\theta}, P_{z}\right),\left(N_{x}\right.$, $\left.N_{\theta}, N_{x \theta}, N_{\theta x}, Q_{x}, Q_{\theta}\right)$ および $\left(M_{x}, M_{\theta}, M_{x \theta}, M_{\theta x}\right)$ で 表示する. 時間を $t$, 弾性係数, ポアンン比, 厚さおよ び単位体積当たりの質量をそれぞれ $E, v, h, \rho$ と表わ す.ここで，次式で定義される時間と経線方向座標の無 次元量 $(\tau, \xi)$ および演算子を導入する.

$$
\begin{aligned}
& \tau=c t / a, \xi=x / l \\
& ()^{\prime}=\partial() / \partial \xi,()^{*}=\partial() / \partial \theta \\
& ()^{\circ}=\partial() / \partial \tau
\end{aligned}
$$

ここに, $c^{2}=E / \rho\left(1-\nu^{2}\right), a=$ 代表長さ, $l=$ 経線の長 さである. 款の半径を $R$, 主曲率半径を $R_{1}, R_{2}$ とすれ ば, 無次元化曲率 $r_{1}\left(=a / R_{1}\right), r_{2}\left(=a / R_{2}\right)$ と無次元化 半径 $r(=R / a)$ の間の関係式は次式となる.

$$
\begin{aligned}
& r_{1} r_{2}=-\left(\gamma^{\prime}+\gamma^{2}\right) / s^{2}=-r^{\prime \prime} / r s^{2} \\
& r_{2}^{\prime}=\gamma\left(r_{1}-r_{2}\right) \\
& r_{2}=\sqrt{1-r^{\prime \prime} / s^{2}} / r
\end{aligned}
$$

ここに, $\gamma=r^{\prime} / r, s=l / a$ である.

さて，構成方程式は次のように与えられる.

$$
\begin{aligned}
& N_{x}=K\left\{\varepsilon_{x}+\nu \varepsilon_{\theta}+\delta\left(r_{1}-r_{2}\right)\left(r_{1} \varepsilon_{x}-a \chi_{x}\right)\right\} \\
& N_{x \theta}=G h\left\{\beta_{x}+\beta_{\theta}+\delta\left(r_{1}-r_{2}\right)\left(r_{1} \beta_{x}-a \bar{\beta}_{x}\right)\right\} \\
& M_{x}=D\left\{\chi_{x}+\nu \chi_{\theta}-\left(r_{1}-r_{2}\right) \varepsilon_{x} / a\right\} \\
& M_{x \theta}=G h^{3}\left[\bar{\beta}_{x}+\bar{\beta}_{\theta}-\left(r_{1}-r_{2}\right) \beta_{x} / a\right\} / 12 \\
& Q_{x}=\chi G h\left\{1+\delta r_{1}\left(r_{1}-r_{2}\right)\right\} \mu_{x}
\end{aligned}
$$

ここに, $K=E h /\left(1-\nu^{2}\right), D=E h^{3} / 12\left(1-\nu^{2}\right), G=$ $E / 2(1+\nu), \delta=h^{2} / 12 a^{2}, x=$ せん断補正係数である. 他の構成方程式は式 (3) で, 添字 $x$ と $\theta$ を交換し, また $r_{1}$ を $r_{2}$ に， $r_{2}$ を $r_{1}$ に置き換えればよい，さらに， ひずみと変位関係式などは次式で与えられる。

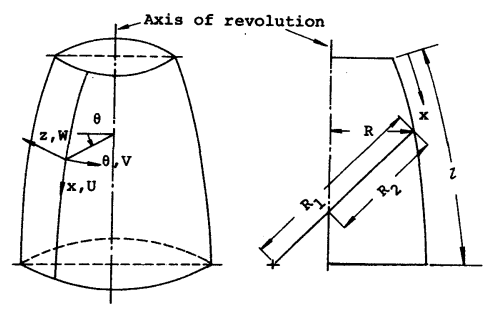

Fig. 1 Typical shell of revolution.
$\varepsilon_{x}=U^{\prime} / s+r_{1} W / a$,

$\varepsilon_{\theta}=\left(V^{*}+r^{\prime} U / s+r r_{2} W\right) / a r$

$\chi_{x}=\Phi_{x}^{\prime} / s, \chi_{\theta}=\left(\Phi_{\theta}^{*}+r^{\prime} \Phi_{x} / s\right) / a r$

$\beta_{x}=V^{\prime} / s, \beta_{\theta}=\left(U^{*}-r^{\prime} V / s\right) / a r$

$\bar{\beta}_{x}=\Phi_{\theta}^{\prime} / s, \bar{\beta}_{\theta}=\left(\Phi_{x}^{*}-r^{\prime} \Phi_{\theta} / s\right) / a r$

$\mu_{x}=W^{\prime} / s-r_{1} U / a+\Phi_{x}$

$u_{\theta}=\left(W^{*}-r r_{2} V\right) / a r+\Phi_{\theta}$

運動方程式は次のように表わされる.

$$
\begin{aligned}
& N_{x}^{\prime} / s+\gamma\left(N_{x}-N_{\theta}\right) / s+N_{\theta x}^{*} / r+r_{1} Q_{x}= \\
& a P_{x}+\rho h c^{2}\left(f_{11} \ddot{U} / a+f_{14} \ddot{\Phi}_{x}\right) \\
& N_{x \theta}^{\prime} / s+\gamma\left(N_{x \theta}+N_{\theta x}\right) / s+N_{\theta}^{*} / r+r_{2} Q_{\theta}= \\
& a P_{\theta}+\rho h c^{2}\left(f_{22} \ddot{V} / a+f_{25} \ddot{\Phi}_{\theta}\right) \\
& Q_{x}^{\prime} / s+\gamma Q_{x} / s+Q_{\theta}^{*} / r-r_{1} N_{x}-r_{2} N_{\theta}= \\
& a P_{z}+\rho h c^{2} f_{33} \ddot{W} / a \\
& M_{x}^{\prime} / s+\gamma\left(M_{x}-M_{\theta}\right) / s+M_{\theta x}^{*} / r-a Q_{x}= \\
& \rho h c^{2}\left(f_{41} \ddot{U}+a f_{44} \ddot{\Phi}_{x}\right) \\
& M_{x \theta}^{\prime} / s+\gamma\left(M_{x \theta}+M_{\theta x}\right) / s+M_{\theta}^{*} / r-a Q_{\theta}= \\
& \rho h c^{2}\left(f_{52} \ddot{V}+a f_{55} \ddot{\Phi}_{\theta}\right)
\end{aligned}
$$

ここに,

$$
\begin{aligned}
& f_{11}=f_{22}=f_{33}=1+\delta r_{1} r_{2} \\
& f_{14}=f_{25}=f_{41}=f_{52}=\delta\left(r_{1}+r_{2}\right) \\
& f_{44}=f_{55}=\delta
\end{aligned}
$$

であり， $f_{i j}$ は後述する式（9) に現われる行列 $\boldsymbol{F}$ の非 零成分を表わす。

境界条件は, 次の 5 組の対の適当な組合せによって構 成される.

$$
\begin{aligned}
& W \text { or } Q_{x}, U \text { or } N_{x}, V \text { or } N_{x \theta} \\
& \Phi_{x} \text { or } M_{x}, \Phi_{\theta} \text { or } M_{x \theta}
\end{aligned}
$$

変位 $\left(U, V, W, \Phi_{x}, \Phi_{\theta}\right)$ と荷重 $\left(P_{x}, P_{\theta}, P_{z}\right)$ を, $\left(u, v, w, \phi_{x}, \phi_{\theta}\right)$ 之 $\left(p_{x}, p_{\theta}, p_{z}\right)$ を係数とする形で, 合応力 $\left(N_{x}, N_{\theta}, N_{x \theta}, N_{\theta x}, Q_{x}, Q_{\theta}\right)$ と曲げモーメント $\left(M_{x}, M_{\theta}, M_{x \theta}, M_{\theta x}\right)$ を, $\left(n_{x}, n_{\theta}, n_{x \theta}, n_{\theta x}, q_{x}, q_{\theta}\right)$ と $\left(m_{x}, m_{\theta}, m_{x \theta}, m_{\theta x}\right)$ を係数亡する形で周方向に Fourier 級数展開する. 代表応力を $\sigma$, 周方向波数を $n$ と記し，正弦展開されるもののみを示すと，

$$
\begin{aligned}
& V=\left(\sigma a^{2} / E h\right) \sum v^{(n)} \sin n \theta \\
& \Phi_{\theta}=(\sigma a / E h) \sum_{n}^{n} \phi_{\theta}^{(n)} \sin n \theta \\
& P_{\theta}=\sigma \sum_{n} p_{\theta}^{(n)} \sin n \theta \\
& \left(N_{\theta}, N_{x \theta}, N_{\theta x}, Q_{\theta}\right)= \\
& \quad \sigma a \sum_{n}\left(n_{\theta}^{(n)}, n_{x \theta}^{(n)}, n_{\theta x}^{(n)}, q_{\theta}^{(n)}\right) \sin n \theta \\
& \left(M_{\theta}, M_{x \theta}, M_{\theta x}\right)= \\
& \quad \sigma a^{2} \sum_{n}\left(m_{\theta}^{(n)}, m_{x \theta}^{(n)}, m_{\theta x}^{(n)}\right) \sin n \theta
\end{aligned}
$$

となる．以下では Fourier 係数の添字 $(n)$ は省略する.

さて, 以上の諸式を用いれば，任意回転殼の運動方程 式は変位成分に関する 2 階 5 元偏微分方程式として次の 
ように得られる.

$$
\boldsymbol{C} \boldsymbol{X}^{\prime \prime}+\boldsymbol{D} \boldsymbol{X}^{\prime}+\boldsymbol{E} \boldsymbol{X}=\left(1-\nu^{2}\right) \boldsymbol{P}+\boldsymbol{F} \ddot{\boldsymbol{X}}
$$

ここに,

$$
\begin{aligned}
& \boldsymbol{X}^{T}=\left(u, v, w, \phi_{x}, \phi_{\theta}\right) \\
& \boldsymbol{P}^{T}=\left(p_{x}, p_{\theta}, p_{z}, 0,0\right)
\end{aligned}
$$

であり, $\boldsymbol{C}, \boldsymbol{D}, \boldsymbol{E}$ と $\boldsymbol{F}$ は, 殸の幾何学的諸量 $r, r_{1}$, $r_{2}, \gamma$ および $r_{1}^{\prime}$ で表わされる $5 \times 5$ 次の行列である $(\boldsymbol{F}$ の非零成分は式 (6) で与えられ, 他の行列のそれは付

録 Iを参照されたい).

境界条件の規定に必要な合応力と曲げモーメントの

Fourier 係数は次のように行列表示される.

$$
\boldsymbol{T}^{T}=\boldsymbol{G} \boldsymbol{X}^{\prime}+\boldsymbol{H} \boldsymbol{X}
$$

ここに,

$$
\boldsymbol{T}^{\mathrm{T}}=\left(n_{x}, n_{x \theta}, q_{x}, m_{x}, m_{x \theta}\right)
$$

であり, $5 \times 5$ 次の行列 $\boldsymbol{G}$ と $\boldsymbol{H}$ の非零成分は付録 I を参 照されたい。

\section{3. 解 析 法}

\section{（1）選点法による空間領域の離散化}

Fig. 2 (a) に示すように回転軸に沿って $N$ 個の要素 に分割する． $k$ 番目の要素を $(k)$ 要素と名付け，境界 条件が指定される殼の両端を $1, N+1$, 分割点を 2,3 , $\cdots, N$ と番号付けをする. 各要素（経線の長さ $l_{k}$ ) で 成立する基礎式の位置に関する独立変数 $\xi$ は $0 \leq \xi \leq 1$ で定義されるものとする.

さて, 選点法による空間領域の近似過程は文献 2) に 従うので,ここでは後の展開で必要なことのみを記す.

(1) 内部選点と端点; Fig.2 (b) に示すように各要素 の経線に沿って $0=\xi_{0}<\xi_{1}<\cdots<\xi_{M}<\xi_{M+1}=1$ の $M+2$ 個 の点を配置する. 内部選点 $\xi_{j}(j=1 \sim M, M=$ 内部選 点数）には，区間 $[0,1]$ で定義される $M$ 次の shifted Legendre 多項式の零点を採用する. $\xi_{0}=0$ と $\xi_{M+1}=1$ は, 境界条件が指定される点や分割点に配置されるもので, 端点とよぶことにする.

(2) 行列 $\boldsymbol{A}$ と $\boldsymbol{B}$; 各要素において, 時刻 $\tau$ での $\xi に$ 関する 1,2 階微分を時刻 $\tau$ での内部選点と端点におけ る関数値 (変位の値) に結びつける $(M+2) \times(M+2)$ 次の行列である（具体的な内容は文献 2$)$ を参照された

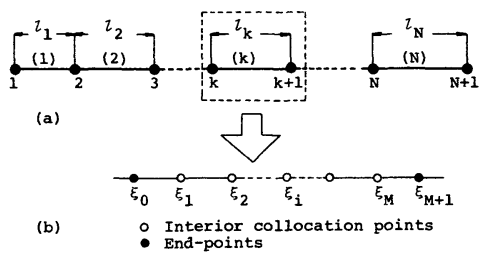

Fig. 2 Shell element:(a) Division of shell into $N$ elements ; (b) Location of collocation points in element $(k)$.
(). $(k)$ 要素の変位成分 $\left(u^{(k)}, v^{(k)}, w^{(k)}, \phi_{x}^{(k)}, \phi_{\theta}^{(k)}\right)$ の 1 つを $\boldsymbol{z}^{(k)}$ (以下 $(k)$ 要素に関する諸量には肩添字 $(k)$ をつけて表わす）と記せば，次のような関係式となる.

$$
\boldsymbol{Z}^{\prime(k)}=\boldsymbol{A} \boldsymbol{Z}^{(k)}, \boldsymbol{Z}^{\prime \prime(k)}=\boldsymbol{B} \boldsymbol{Z}^{(k)}
$$

ここに， $(\boldsymbol{M}+2) \times 1$ 次のベクトル，たとえば $\boldsymbol{Z}^{(k)}$ は次 のようなものである.

$$
\mathbf{Z}^{(k) T}=\left(Z\left(\xi_{0}\right)^{(k)}, Z\left(\xi_{1}\right)^{(k)}, \cdots, Z\left(\xi_{M+1}\right)^{(k)}\right)
$$

(3) $\boldsymbol{Z}_{c}^{(k)}$ と $\boldsymbol{Z}_{e}^{(k)}$; 式 (14) は内部選点と端点に関する成 分より構成されている．以下ではこれらを分離し，内部 選点に関するものには添字 $c$ を，端点のそれには添字 $e$ を付して表わす。

$$
\left.\begin{array}{l}
Z_{c}^{(k) T}=\left(Z\left(\xi_{1}\right)^{(k)}, Z\left(\xi_{2}\right)^{(k)}, \cdots, Z\left(\xi_{M}\right)^{(k)}\right) \\
Z_{e}^{(k) T}=\left(Z\left(\xi_{0}\right)^{(k)}, Z\left(\xi_{M+1}\right)^{(k)}\right)
\end{array}\right\}
$$

未知量を内部選点と端点に関するものに分離する操作 は，後に示すように解法の展開が簡潔に行え，また次元 の高い方程式の求解過程を回避できる解法の開発を可能 にしている.

以上の準備のもとに, $N$ 個の要素分割による $5(M+2)$ $N$ 個の未知数に対する条件は次のように与えられる.

a) 基礎微分方程式の残差の条件（5MN 個の条件）

この条件は, 基礎微分方程式（9）の内部選点におけ る残差の条件より求められる. $(k)$ 要素に着目すれば, 最終的に次の時間に関するマトリックス常微分方程式を 得る.

$$
\begin{array}{r}
\boldsymbol{\alpha}_{c}^{(k)} \boldsymbol{\delta}_{c}^{(k)}+\boldsymbol{\alpha}_{e}^{(k)} \boldsymbol{\delta}_{e}^{(k)}=\boldsymbol{P}_{c}^{(k)}+\boldsymbol{\beta}_{c}^{(k)} \ddot{\boldsymbol{\delta}}_{c}^{(k)} \\
(k=1 \sim N) \cdots \cdots \cdots \cdots
\end{array}
$$

ここに, 添字 $c$ と $e$ はそれぞれ内部選点, 端点に関す る行列やベクトルを表わす. ベクトルの内容を式 (15) の表わし方に従って示すと次式となる.

$$
\begin{aligned}
\boldsymbol{\delta}_{c}^{(k) T}= & \left(\boldsymbol{u}_{c}^{(k) T}, \boldsymbol{v}_{c}^{(k) T}, \boldsymbol{w}_{c}^{(k) T}, \boldsymbol{\phi}_{x c}^{(k) T}, \boldsymbol{\phi}_{\theta c}^{(k) T}\right)_{1 \times 5 M} \\
\boldsymbol{\delta}_{e}^{(k) T}= & \left(\boldsymbol{u}_{e}^{(k) T}, \boldsymbol{v}_{e}^{(k) T}, \boldsymbol{w}_{e}^{(k) T}, \boldsymbol{\phi}_{x e}^{(k) T}, \boldsymbol{\phi}_{\theta e}^{(k)}\right)_{1 \times 10} \\
\boldsymbol{P}_{c}^{(k) T}= & \left(\left(1-\nu^{2}\right) \boldsymbol{P}_{x}^{(k) T},\left(1-\nu^{2}\right) \boldsymbol{P}_{\theta}^{(k) T},\right. \\
& \left.\left(1-\nu^{2}\right) \boldsymbol{P}_{z}^{(k) T}, \mathbf{0 , 0}\right)_{1 \times 5 M} \\
\ddot{\boldsymbol{\delta}}_{c}^{(k) T}= & \left(\ddot{\boldsymbol{u}}_{c}^{(k) T}, \ddot{v}_{c}^{(k) T}, \ddot{\boldsymbol{w}}_{c}^{(k) T}, \ddot{\boldsymbol{\phi}}_{x c}^{(k) T}, \boldsymbol{\phi}_{\theta c}^{(k) T}\right)_{1 \times 5 M}
\end{aligned}
$$

さらに, $\boldsymbol{\alpha}_{c}^{(k)}$ と $\boldsymbol{\alpha}_{e}^{(k)}$ は, 式 $(9)$ に現われる $\xi$ 微分階 数に応じて, 式 (13) の行列 $\boldsymbol{A}$ と $\boldsymbol{B}$ の成分で構成され るそれぞれ， $5 M \times 5 M$ と $5 M \times 10$ 次の行列であり， $\boldsymbol{\beta}_{c}^{(k)}$ は慣性力の係数（式（6））を成分とする $5 M \times 5 M$ 次の行列である.なお $\boldsymbol{\alpha}_{c}^{(k)}$ と $\boldsymbol{\alpha}_{e}^{(k)}$ の内容は付録 II を参照 されたい.

b) 境界条件式 (10 個の条件)

10 個の条件は, $(1)$ 要素の境界点 1 と $(N)$ 要素の 境界点 $N+1$ でそれぞれ規定される 5 個の条件より,

$$
\left.\begin{array}{l}
\boldsymbol{\gamma}_{c, 1}^{(1)} \boldsymbol{\delta}_{c}^{(1)}+\boldsymbol{\gamma}_{e, 1}^{(1)} \boldsymbol{\delta}_{e}^{(1)}=\boldsymbol{g}^{(1)} \\
\boldsymbol{\gamma}_{c, N+1}^{(M)} \boldsymbol{\delta}_{c}^{(M)}+\boldsymbol{\gamma}_{e, N+1}^{(M)} \boldsymbol{\delta}_{e}^{(M)}=\boldsymbol{g}^{(M)}
\end{array}\right\}
$$

と得られる。ここに，コンマ(, ) の後の下付き添字 $i$ $(=1, N+1)$ は境界点を表わす. $\boldsymbol{\gamma}_{c, 1}^{(1)}$ と $\gamma_{c, N+1}^{(M)}$ および 
$\boldsymbol{\gamma}_{e, 1}^{(1)}$ と $\boldsymbol{\gamma}_{e, N+1}^{(M)}$ は, 式 (13) の行列 $\boldsymbol{A}$ の成分で構成される それぞれ $5 \times 5 M, 5 \times 10$ 次の行列であり, $\boldsymbol{g}^{(1)}$ と $\boldsymbol{g}^{(M)}$ あらかじめ規定された変位, 応力などの值を成分とする $5 \times 1$ 次のベクトルである.

c）分割点における接続条件式 $(10(N-1)$ 個の条 件)

この条件は, 分割点 $i(=2 \sim N)$ で成立する変形量 $\boldsymbol{X}$ （式（10））亡力学量 $\boldsymbol{T}$ (式 (12)）の接続条件で与え られる. すなわち, 次式より求められる.

$\boldsymbol{X}^{(i-1)}=\boldsymbol{X}^{(i)}, \quad \boldsymbol{T}^{(i-1)}=\boldsymbol{T}^{(i)}$

ここに, $i=2 \sim N$ であり, 添字 $(i-1),(i)$ の諸量は, それぞれ $\xi=\xi_{M+1}, \xi=\xi_{0}$ の值をとる. 上式の一般形を 式 (18) に習い行列表示すると次式となる.

$$
\begin{gathered}
\boldsymbol{\gamma}_{c, i}^{(i-1)} \boldsymbol{\delta}_{c, i}^{(i-1)}+\boldsymbol{\gamma}_{e, i}^{(i,-1)} \boldsymbol{\delta}_{e, i}^{(i,-1)}+\boldsymbol{\gamma}_{c, i}^{(i)} \boldsymbol{\delta}_{c, i}^{(i)} \\
+\boldsymbol{\gamma}_{e, i}^{(i)} \boldsymbol{\delta}_{e, i}^{(i)}=\mathbf{0} \\
(i=2 \sim N) \cdots
\end{gathered}
$$

ここに, $\gamma_{c, i}^{(\prime)}$ おび $\gamma_{e, i}^{\prime \prime}$ は，それぞれ $10 \times 5 M, 10 \times 10$ 次の行列で, 式 (13) の行列 $\boldsymbol{A}$ の成分で構成される. 下付き添字 $i$ は分割点を表わす.

\section{（2）時間領域の離散化}

前節で, 選点法を適用して空間を離散化し, その結果, 式 (16)，(18）および式 (20) の時間に関する $5(M+2)$ $N$ 本の方程式が得られた。本節では，これらに直接積 分法を適用し時間方向の近似を行う.一般に積分法には, 構造振動問題には無条件安定な陰公式が用いられ, 波動 伝播問題には陽公式が用いられるが，ここでは双方によ る解析の手順を具体的に示すために, 陰公式には代表的 に Houbolt 法4) ，陽公式には代表的に中心差分法を採 用する.また，選点法本来の利点である未知数の個数の 減少は, 波動伝播の問題にも生かされるが, 構造振動問 題の場合に比べてある程度の自由度数の増加は避けられ ない.したがって，いかにして次元の高い行列の演算を 回避するかがここでの課題の 1 つであり, この点も含め て以下に具体的な解析アルゴリズムを提示する. なお, 展開を容易にするため初期条件は零とした。

\section{a）陰公式による場合}

陰公式による場合には, FEM で知られている部分構 造法に類似な手法を導入することにより, 解くべき方程 式は比較的小さな方程式へと変換できる. すなわち,こ こでは 1 つの要素を部分構造とみなし, まず系全体の端 点における未知量を求めた後, 各部分構造を独立に既知 の端点の変位のもとで解析する.

式（16）に Houbolt 法を適用すれば, 時刻 $\tau=\tau_{0}+$ $j \cdot \Delta \tau\left(\tau_{0}=\right.$ スタート時刻, $\Delta \tau=$ 時間間隔, $j=$ 時間ステッ プ）で成立する次式を得る.

$\boldsymbol{K}_{c}^{(k)} \boldsymbol{\delta}_{c, j}^{(k)}+\boldsymbol{\alpha}_{e}^{(k)} \boldsymbol{\delta}_{e, j}^{(k)}=S_{c, j}^{(k)} \quad(k=1 \sim N)$

ここに,

$$
\begin{aligned}
& j=1 ; \boldsymbol{K}_{c}^{(k)}=\boldsymbol{\alpha}_{c}^{(k)}-6 \boldsymbol{\beta}_{c}^{(k)} / \Delta \tau^{2} \\
& \boldsymbol{S}_{c, 1}^{(k)}=2 \boldsymbol{P}_{c, 1}^{(k)}+\boldsymbol{P}_{c, 0}^{(k)} \\
& j=2 ; \boldsymbol{K}_{c}^{(k)}=\boldsymbol{\alpha}_{c}^{(k)}-2 \boldsymbol{\beta}_{c}^{(k)} / \Delta \tau^{2} \\
& \boldsymbol{S}_{c, 2}^{(k)}=\boldsymbol{P}_{c, 2}^{(k)}+\boldsymbol{P}_{c, 0}^{(k)}-4 \boldsymbol{\beta}_{c}^{(k)} \boldsymbol{\delta}_{c, 1}^{(k)} / \Delta \tau^{2} \\
& j \geq 3 ; \boldsymbol{K}_{c}^{(k)}=\boldsymbol{\alpha}_{c}^{(k)}-2 \boldsymbol{\beta}_{c}^{(k)} / \Delta \tau^{2} \\
& \boldsymbol{S}_{c, j}^{(k)}=\boldsymbol{P}_{c, j}^{(k)}-\boldsymbol{\beta}_{c}^{(k)}\left(\mathbf{5}_{c, j-1}^{(k)}\right. \\
& -4 \delta_{c, j-2}^{(k)}+\delta_{c, j-3}^{(k)} / \Delta \tau^{2}
\end{aligned}
$$

であり, コンマ (, ) の後の添字は時間ステップを表わ す.

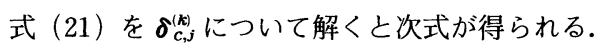

$\boldsymbol{\delta}_{c, j}^{(k)}=\boldsymbol{K}_{c}^{(k)-1}\left(\boldsymbol{S}_{c, j}^{(k)}-\boldsymbol{\alpha}_{e}^{(k)} \boldsymbol{\delta}_{e, j}^{(k)}\right)$

上式を, 添字 $(k)$ に留意して, 式 (18), (20) に代入 すれば, 端点における変形を未知量とする次式を得る.

$\boldsymbol{K}_{e} \boldsymbol{\delta}_{e, j}=\overline{\boldsymbol{S}}_{j}$

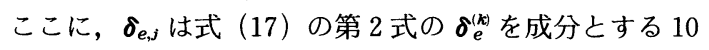
$N \times 1$ 次のベクトルである.

$$
\delta_{e, j}^{T}=\left(\boldsymbol{\delta}_{e, j}^{(1) T}, \boldsymbol{\delta}_{e, j}^{(2) T}, \cdots, \boldsymbol{\delta}_{e, j}^{(N) T}\right) \cdots
$$

さらに, 大きさが内部選点数に依存しない $10 N \times 10 N$ 次の行列 $\boldsymbol{K}_{\boldsymbol{e}}$ と大きさ $10 \mathrm{~N} \times 1$ 次のベクトル $\overline{\boldsymbol{S}}_{\boldsymbol{j}}$ は,

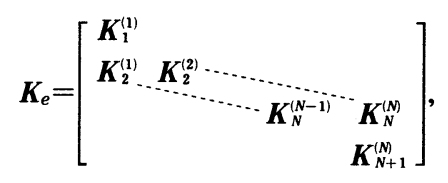

$\overline{\boldsymbol{S}}_{j}=\left|\begin{array}{c}\overline{\boldsymbol{S}}_{1, j} \\ \overline{\boldsymbol{S}}_{2, j} \\ \vdots \\ \overline{\boldsymbol{S}}_{N, j} \\ \overline{\boldsymbol{S}}_{N+1, j}\end{array}\right|$

と表わされる.ここに，

$$
\begin{aligned}
\boldsymbol{K}_{i}^{(i)}=\boldsymbol{\gamma}_{e, i}^{(i)}-\boldsymbol{\gamma}_{c, i}^{(i)} \boldsymbol{K}_{c}^{(i)-1} \boldsymbol{\alpha}_{e}^{(i)} \quad(i=1 \sim N) \\
\boldsymbol{K}_{i}^{(i-1)}=\boldsymbol{\gamma}_{e, i}^{(i-1)}-\boldsymbol{\gamma}_{c, i}^{(i-1)} \boldsymbol{K}_{c}^{(i-1)-1} \\
\quad \cdot \boldsymbol{\alpha}_{e}^{(i-1)} \quad(i=2 \sim N+1) \\
\overline{\boldsymbol{S}}_{1, j}=\boldsymbol{g}^{(1)}-\boldsymbol{\gamma}_{c, 1}^{(1)} \boldsymbol{K}_{c}^{(1)-1} \boldsymbol{S}_{c, j}^{(1)} \\
\overline{\boldsymbol{S}}_{i, j}=-\boldsymbol{\gamma}_{c, j}^{(i-1)} \boldsymbol{K}_{c}^{(i-1))^{-1}} \boldsymbol{S}_{c, j}^{(i-1)} \\
\quad-\boldsymbol{\gamma}_{c, i}^{(i)} \boldsymbol{K}_{c}^{(i)-1} \boldsymbol{S}_{c, j}^{(i)} \quad(i=2 \sim N) \\
\overline{\boldsymbol{S}}_{N+1, j}=\boldsymbol{g}^{(M)}-\boldsymbol{\gamma}_{c, N+1}^{(M)} \boldsymbol{K}_{c}^{()_{c}^{-1}} \boldsymbol{S}_{c, j}^{(M)}
\end{aligned}
$$

ここでの計算過程を要約すると, まず式 $(24)$ より端 点における未知量を求め, 次に式 (23) より各要素の内 部選点における未知量を既知の端点の変位のもとで求め ることになる。

\section{b ）陽公式による場合}

ここでは, 中心差分法を用いるが，スタート時に特別 な扱いが必要なので, 厳密には時間ステップ $j \geq 2$ で中 心差分法を用いたことになる.

（イ） $j=1\left(\tau=\tau_{0}+\Delta \tau\right)$ のとき $\tau=\tau_{0}$ での速度を中心差分, $\tau=\tau_{0}+\Delta \tau$ での加速度を 
後退差分で表わした後, 初期条件 (ここでは零とする) を考慮すれば, $j=1$ での加速度は $\ddot{\delta}_{c}^{(k)}=2 \delta_{c}^{(k)} / \Delta \tau^{2}$ とな る.したがって, 式 (16) は次のようになる.

$$
\left(\boldsymbol{\alpha}_{c}^{(k)}-2 \boldsymbol{\beta}_{c}^{(k)} / \Delta \tau^{2}\right) \boldsymbol{\delta}_{c, 1}^{(k)}+\boldsymbol{\alpha}_{e}^{(k)} \delta_{e, 1}^{(k)}=\boldsymbol{P}_{c, 1}^{(k)} \quad(k=1 \sim N)
$$

上式は式（21）と同形なので, a) で述べた計算手順に よりすべての未知量が求められる.

(口) $j \geq 2\left(\tau=\tau_{0}+j \Delta \tau\right)$ のとき

加速度を中心差分で表わすと，式（16）は,

$$
\begin{aligned}
\boldsymbol{\beta}_{c}^{(k)} \boldsymbol{\delta}_{c, j}^{(k)} / \Delta \tau^{2}= & \left(\boldsymbol{\alpha}_{c}^{(k)}+2 \boldsymbol{\beta}_{c}^{(k)} / \Delta \tau^{2}\right) \boldsymbol{\delta}_{c, j-1}^{(k)}+\boldsymbol{\alpha}_{e}^{(k)} \boldsymbol{\delta}_{e, j-1}^{(k)} \\
& -\boldsymbol{P}_{c, j-1}^{(k)}-\boldsymbol{\beta}_{c}^{(k)} \boldsymbol{\delta}_{c, j-2}^{(k)} / \Delta \tau^{2} \\
& (k=1 \sim N) \ldots \ldots \ldots \ldots \ldots \ldots \ldots \ldots \ldots \ldots \ldots \ldots \ldots \ldots \ldots \ldots \ldots
\end{aligned}
$$

と整理される.上式の右辺は既知亡なるので, 各要素の 内部選点における変位 $\boldsymbol{\delta}_{c, j}^{(k)}$ は独立に解かれる.

次に, 式 (29) より得られた $\boldsymbol{\delta}_{c, j}^{(k)}$ を式 (18)，(20)に 代入すれば, 端点における変位 $\boldsymbol{\delta}_{e, j}^{(k)}$ を末知量とする式 （24）の形で整理できる. ただし，式 (27) の行列とべク トルは次のように修正される.

$$
\begin{aligned}
& \boldsymbol{K}_{i}^{(i)}=\boldsymbol{\gamma}_{e, i}^{(i)} \quad(i=1 \sim N) \\
& \boldsymbol{K}_{i}^{(i-1)}=\boldsymbol{\gamma}_{e, i}^{(i-1)} \quad(i=2 \sim N+1) \\
& \overline{\boldsymbol{S}}_{1, j}=\boldsymbol{g}^{(1)}-\boldsymbol{\gamma}_{c, \mathbf{1}}^{(1)} \boldsymbol{\delta}_{c, j}^{(1)} \\
& \overline{\boldsymbol{S}}_{i, j}=-\boldsymbol{\gamma}_{c, i}^{(i-1)} \boldsymbol{\delta}_{c, j}^{(i-1)}-\boldsymbol{\gamma}_{c, i}^{(i)} \boldsymbol{\delta}_{c, j}^{(i)} \quad(i=2 \sim N) \\
& \overline{\boldsymbol{S}}_{N+1, j}=\boldsymbol{g}^{(N)}-\boldsymbol{\gamma}_{c, N+1}^{()} \boldsymbol{\delta}_{c, j}^{(M)}
\end{aligned}
$$

$j \geq 2$ での計算手順は, まず各要素の内部選点におけ る未知量を独立に求め, 次にこれをもとに系全体の端点 における末知量を求めることになる。これは, 陰公式で の手順と逆であり興味深い.なお，ここでの計算手順は, 選点法と陰公式の組合せの場合に用いたような技巧を必 要とせす，選点法と陽公式の組合せに対して必然的に得 られるものである.

\section{（3）時間間隔 $\Delta \tau$ の設定}

時間間隔は, 陽および陰公式とも, 最小の経線の長さ $\left(S_{\min }\right)$ の要素内に選ばれた一連の点 $\xi_{i}(i=0,1, \cdots, M$ $+1)$ の最小間隔 $\left(\xi_{\min }\right)$ を縦波が伝播するのに要する時 間を基準に設定する.

$$
\Delta \tau \leq S_{\min } \cdot \xi_{\min }
$$

ここで, $S_{\min }$ および $\xi_{\min }$ はそれぞれ, 要素の経線の長 さ $l_{i}\left(=S_{i} / a, a=\right.$ 代表長さ) および区間 $[0,1]$ 内に とられる内部選点の分布状況 (区間の端で密, 中央で粗, $\xi=0.5$ に関して対称）より次のように与えられる.

$$
\begin{aligned}
& S_{\min }=\min \left(S_{i}\right) \quad(i=1 \sim N) \\
& \xi_{\min }=\xi_{1}-\xi_{0} \quad\left(=\xi_{M+1}-\xi_{M}\right) \cdots \cdots
\end{aligned}
$$

参考のため, Table 1 に数種の内部選点数 $M$ に対する $\xi_{\min }$ の值を示す.

さて中心差分法による場合は, 安定条件として次の条 件を要する ${ }^{5), 6)}$.

$$
\Delta \tau \leq \min \left(2 / \lambda_{\max }^{(k)}\right) \quad(k=1 \sim N)
$$

Table 1 Values of $\xi_{\text {min }}$.

\begin{tabular}{|c|c||c|c|}
\hline $\mathrm{M}$ & $\xi_{\text {min }}$ & iI & $\xi_{\text {min }}$ \\
\hline 5 & 0.0469 & 9 & 0.0159 \\
6 & 0.0338 & 10 & 0.0130 \\
7 & 0.0254 & 11 & 0.0109 \\
8 & 0.0199 & 12 & 0.0092 \\
\hline
\end{tabular}

ただし空間領域を選点法により離散化する本手法の場 合, $\lambda_{\max }^{(k)}$ は $(k)$ 要素の両端が完全固定 $(\boldsymbol{X}=\mathbf{0}$, 式 $(10))$ されたときの無次元化固有振動数 $\lambda(=\omega a / c, \omega=$ 固 有円振動数) の最大值である. 完全固定の条件が関与す るのは空間に対して用いた選点法の特性に由来するもの であり，以下これについて説明を加える.

選点法を要素の両端が任意支持の場合の固有振動問題 に適用する ${ }^{7)}$. 式 (16) で, $\delta_{c}^{(k)}, \delta_{e}^{(k)} \propto e^{i \omega a \tau / c}$ および $\boldsymbol{P}_{c}^{(k)}=\mathbf{0}$ とおけば次式を得る.

$$
\boldsymbol{\alpha}_{c}^{(\boldsymbol{k})} \boldsymbol{\delta}_{c}^{(k)}+\boldsymbol{\alpha}_{e}^{(\boldsymbol{k})} \boldsymbol{\delta}_{e}^{(\boldsymbol{k})}+\lambda^{2} \boldsymbol{\beta}_{c}^{(k)} \boldsymbol{\delta}_{c}^{(k)}=\mathbf{0}
$$

要素の両端で規定される条件は次式で表わされる.

$$
\bar{\gamma}_{c}^{(k)} \delta_{c}^{(k)}+\bar{\gamma}_{e}^{(k)} \delta_{e}^{(k)}=\mathbf{0}
$$

ここに, $\bar{\gamma}_{c}^{(k)}$ と $\bar{\gamma}_{e}^{(k)}$ はそれぞれ, $10 \times 5 M, 10 \times 10$ 次の 行列である. 式 (35), (36) より $\boldsymbol{\delta}_{e}^{(k)}$ を消去すれば, 任 意支持された $(k)$ 要素の固有振動数方程式は, 次のよ うに導かれる。

$$
\begin{gathered}
\left(\boldsymbol{\beta}_{c}^{(k)-1}\left(\boldsymbol{\alpha}_{c}^{(k)}-\boldsymbol{\alpha}_{e}^{(k)} \overline{\boldsymbol{\gamma}}_{e}^{(k)-1} \overline{\boldsymbol{\gamma}}_{c}^{(k)}\right)\right. \\
\left.+\lambda^{2} \boldsymbol{I}\right) \boldsymbol{\delta}_{c}^{(k)}=\mathbf{0} \cdots \cdots \cdots \cdots
\end{gathered}
$$

ここで,Iは単位行列である.

ところで, 差分式 (29) に $\boldsymbol{\delta}_{c, j}^{(k)}=\mu \boldsymbol{\delta}_{c, j-1}^{(k)}(\mu=$ パラメー 夕一）を代入し, 外乱項に相当する右辺の第 2,3 項を 無視すれば次式が得られる.

$$
\left(\beta_{c}^{(k)-1} \alpha_{c}^{(k)}-(\mu-2+1 / \mu) I / \Delta \tau^{2}\right) \delta_{c, j-1}^{(k)}=0
$$

式（37）と式（38）を比較すれば, 次式が成立すると き同じ形の固有値問題亡なる.

$$
\boldsymbol{\alpha}_{e}^{(k)} \bar{\gamma}_{e}^{(k)-1} \bar{\gamma}_{c}^{(k)}=\mathbf{0}
$$

$\lambda^{2}=-(\mu-2+1 / \mu) / \Delta \tau^{2}$

式（39）が成立するのは， $\boldsymbol{\alpha}_{e}^{(\boldsymbol{k})} \overline{\boldsymbol{\gamma}}_{e}^{(\boldsymbol{k})-1} \neq \mathbf{0}$ に留意すれば, $\overline{\boldsymbol{\gamma}}_{c}^{(k)}$ が零行列の場合である. すなわち, 要素の両端で規 定される条件式 (36) において, $\bar{\gamma}_{c}^{(k)}$ が零行列で与えら れる完全固定のときである.このとき式 (37) は次式と なる.

$$
\left(\boldsymbol{\beta}_{c}^{(k)-1} \boldsymbol{\alpha}_{c}^{(k)}+\lambda^{2} \boldsymbol{I}\right) \boldsymbol{\delta}_{c}^{(k)}=\mathbf{0}
$$

したがって, 上式より定まる固有值 $\lambda$ の最大值が式 (34) の $\lambda_{\max }^{(k)}$ を与えることになる. 式 (41) の妥当性につい ては, 次章で数值例をもって例証する.

\section{4. 数値計算例}

本章では, 3. で提示した手法の適用性, 有効性を確 認するため 2 つの数値解析を行った（1）では円筒殼 を取り上げ，本計算值と理論解との比較をすることに 
(a)

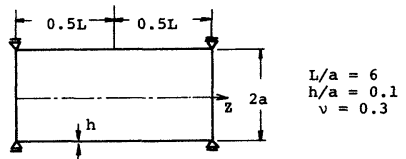

(b)

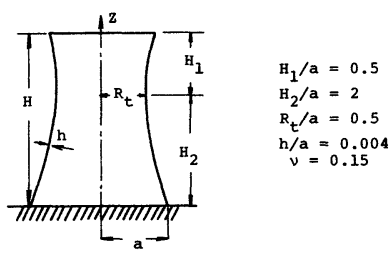

Fig. 3 Shells used for numerical studies: (a) Cylindrical shell ; (b) Hyperboloidal shell.

よって手法の妥当性を検討し，（2）では任意形状の回 転款への一適用例として双曲殼の解析例を示す．なお， 計算に用いたせん断補正係数は $\pi^{2} / 12$ である.

\section{（1）円 筒 殼}

Fig. 3 (a) に示すような寸法・形状をもち, 両端で単 純支持され，スパン中央に $p_{z}=\sigma \cos n \theta$ で表わされる 周方向に $n$ 波の正弦分布する法線方向線荷重がステッ プ関数的に作用する円筒壳を解析する. 問題の対称性か ら全体の $1 / 2$ 部分を解析し, 空間と時間の離散量（空間 に対しては内部選点数 $M$ と分割数 $N$, 時間に対しては 時間間隔 $\Delta \tau$ ）の解に与える影響を検討するため,

Table 2 に示すような 5 種の離散化モデルを選んだ．以 後 Case 1, 2, ․ 5 とよぶことにする. 各 Case におい て，要素分割は等分割である。なお，空間に対する離散 量 $M$ と $N$ は，選点法による前論文 ${ }^{2), 7)}$ の結果を参考に し, 要素内の内部選点数 $M$ は 11 を基準に選び, 要求 される精度に応じて分割数 $N$ を増加させるという立場 から設定したものである。

波数 $n=1$ の外力が作用するときの，支持端からの位
Table 2 Discretization patterns for cylindrical shell.

\begin{tabular}{|c|r|r|l|}
\hline Case & $\mathrm{M}$ & $\mathrm{N}$ & \multicolumn{1}{|c|}{$\Delta \tau$} \\
\hline 1 & 5 & 10 & 0.01 \\
2 & 5 & 10 & 0.005 \\
3 & 11 & 5 & 0.005 \\
4 & 11 & 5 & 0.0025 \\
5 & 11 & 10 & 0.0025 \\
\hline
\end{tabular}

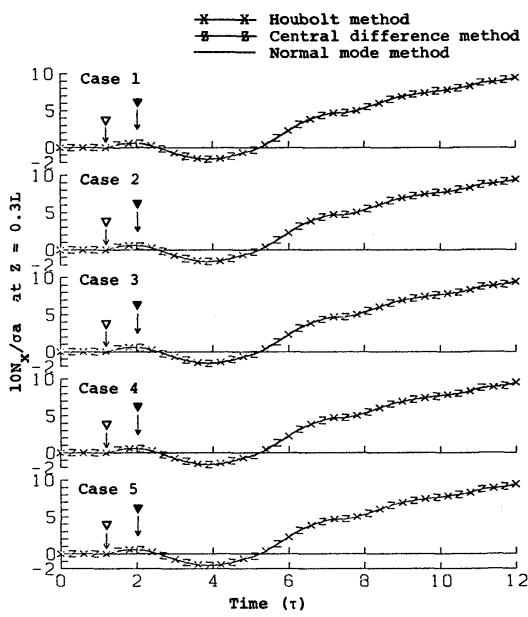

Fig. 4 Effect of discretization patterns on transient response of meridional stress resultant (cylindrical shell).

置 $z=0.3 L$ における合応力 $N_{x}$ および曲げモーメント $M_{x}$ の時間応答を Fig. 4 ， 5 に示す. 図でXおよびZ印 を付した実線は，それぞれ Houbolt 法および中心差分 法による值であり，実線のみのものは比較のために用い たモード解析法 ${ }^{8)}$ の結果（奇数項のみ 128 個の総和）で ある. また図には荷重点より発した縦波（伝播速度= $\left.\sqrt{E / \rho\left(1-\nu^{2}\right)}\right)$ とせん断波（伝播速度 $=\sqrt{G / \rho}$ ) の着目

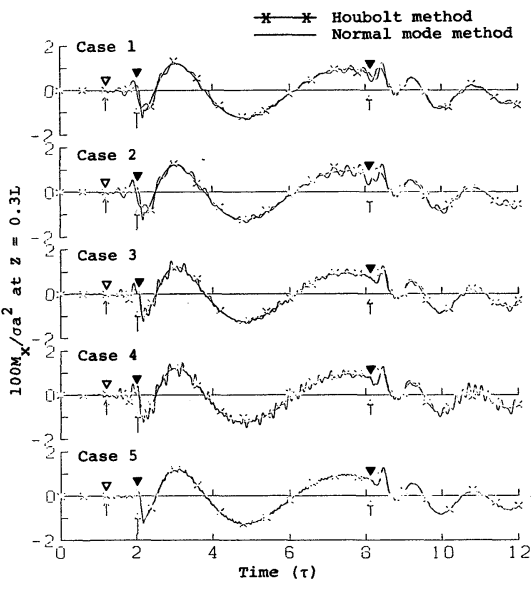

(a) Houbolt method

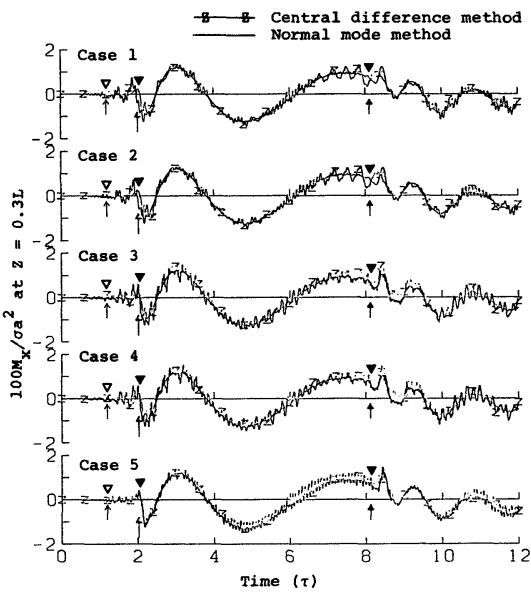

(b) Central difference method

Fig. 5 Effect of discretization patterns on transient response of meridional bending moment (cylindrical shell). 
点での到達時刻の位置がそれぞれ， 印とマ印で示され ている（ただし，Fig. 5 の 2 番目のマ印は, 荷重点より 発したせん断波が支持端で反射され荷重点に最初に到達 する時間を表わす).

合応力 $N_{x}$ (Fig. 4) は, 離散化量 $(M, N, \Delta \tau)$ およ び採用した積分公式によらず，モード解析法の結果とよ い一致を示している.

Fig. 5 (a) は Houbolt 法および Fig. 5 (b) は中心差 分法による曲げモーメント $\boldsymbol{M}_{\boldsymbol{x}}$ の結果を，それぞれ実線 のみで示したモーダル解と比較したものである．本法に よる応答波形は各 Case とも，モード解析法による波形 に高次の振動が重畳した波形となっているが，高次振動 を平均化するとモーダル解の波形にほぼ一致している. 内部選点数 $M$ が小さい場合（Case 1 と2）は，せん断 波の到達前後において波形の乱れが認められるが， $M$ を増せばこの乱れは減少する傾向にあり，また高次振動 の周期と振幅も $M$ を増せば小さくなる傾向にある.さ て, 空間に対する離散化度が同一の場合（Case 1 と 2 , Case 3 と 4), 小さな積分間隔による解と大きなそれに よる解には，あまり差異がない。このことは，前述の高 次振動や乱れが空間領域の離散化に伴う誤差であること を示唆している.

Fig. 6 は, 任意の波数 $n$ を有する荷重条件への本法の 適用性を調べるために，積分法にHoubolt 法を，離散 化モデルにCase 5 を用いたときの, 波数の変化 $(n=$ $2,5,10)$ に対する $N_{x}$ と $M_{x}$ の時間応答を示したもので ある. $N_{x}$ の時間応答は, モード解析法のそれとほとん ど一致し, $M_{x}$ の時間応答には, 波数 $n=1$ のときと同 様に高次の振動が認められるが，高次振動を平均化する とモード解析法の時間応答によく一致している.

次に, 式 (41) より得られる中心差分法の時間間隔に

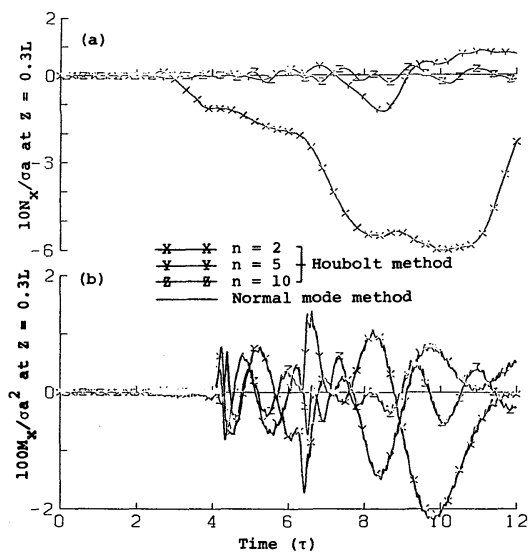

Fig. 6 Transient responses of cylindrical shell for $n=2,5$, and $10:$ (a) Meridional stress resultant; (b) Meridional bending moment.
検討を加える.Fig. 7 は $M=11, \nu=0.3$ の場合について, 時間間隔 $\Delta \tau\left(=2 / \lambda_{\max }, \lambda_{\max }\right.$ は式 $(41)$ より求められ る $\lambda$ の最大値) と $h / a$ (厚さ/半径) の関係を $S$ (要素 の長さ/半径）に対してプロットしたものである.なお， 図は波数 $n=1$ について調べたものであるが， $n \leq 20$ の 範囲については, $n=1$ の結果と比較して数\% 程度の誤 差しか生じないことを確認してある. 図より $\Delta \tau$ は $S$ および $h / a$ が小さくなるにつれて減少しており，中心 差分法は $S$ および $h / a$ が小さい場合には, 少なくとも 計算効率の面では好ましくないことが理解される。

Fig. 8 は Fig. 7 および式 (41) の妥当性を数值的に検 証したものである. 図は, 波数 $n=1$ の場合について, 次に示す 2 種の諸元 (Model A, B と記す) および式 (41) を用いて定めた時間間隔を含む 3 種のそれに対するスパ ン中央の変位 $W$ の時間応答を示している.

Model A $; L / a=6, h / a=0.1$

$\Delta \tau_{1}=0.014, \Delta \tau_{2}=0.013, \Delta \tau_{3}=0.010$

Model B $; L / a=6, h / a=0.05$

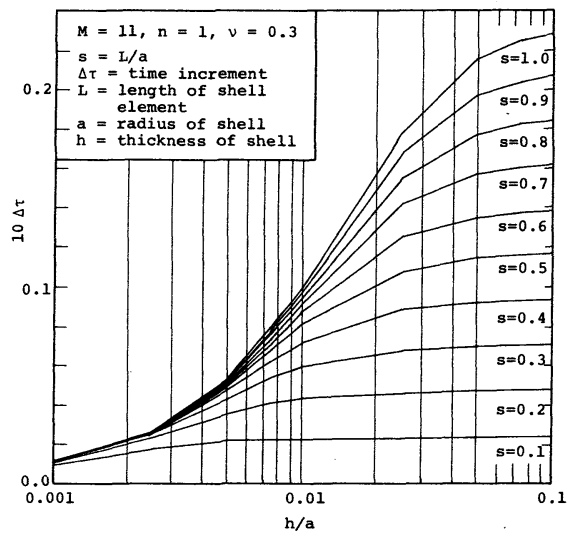

Fig. 7 Relationship between $\Delta \tau, h / a$ and $s$ as predicted by Eq. (41).

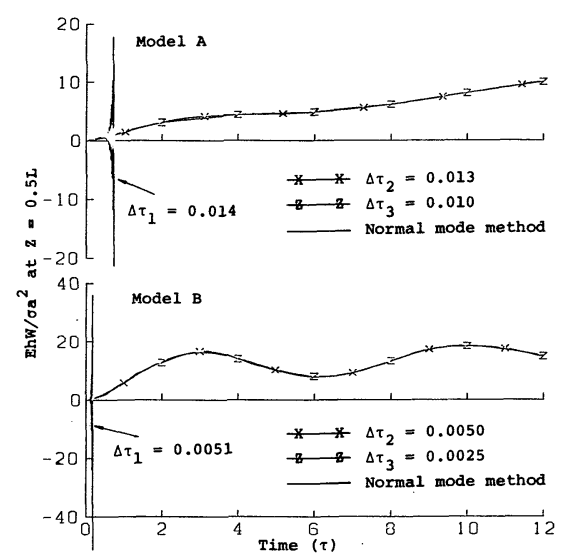

Fig. 8 Effect of time increment on transient response of normal displacement (cylindrical shell). 
$\Delta \tau_{1}=0.0051, \Delta \tau_{2}=0.0050, \Delta \tau_{3}=0.0025$ 時間間隔 $\Delta \tau_{1}$ は式 $(41)$ またはFig.7の $\lambda$ を用いて決 定し，他のそれは $\Delta \tau_{1}$ より小さくなるように任意に定 めた. なお, 内部選点数には $M=11$, 分割数には $N=5$ を用いた。図で， $\Delta \tau_{1}$ に対する結果は応答初期で不安定 (発散)となり，他の $\Delta \tau$ に対する応答は安定した解を 示している. このように，要素の両端を完全固定として 導かれた式（41）の最大固有振動数は，中心差分法によ る時間間隔を定めるのに有効である.

\section{（2）片持ち形式の双曲殼}

本法の任意回転殼への適用例として, Fig. 3 (b) に 示す形状・寸法をもち，自由端に沿って面外方向線荷重 $\sigma \cos \theta$ と面内方向線荷重 $\sigma \sin \theta$ がステップ関数的に作 用する双曲殼を解析する．要素分割は，スロート部より 上部を回転軸に沿って 3 等分割，下部を同様に 12 等分 割した計 15 要素であり, 内部選点数は $M=11$ とした. 積分法には，Houbolt 法を用い，時間間隔は $\Delta \tau=$

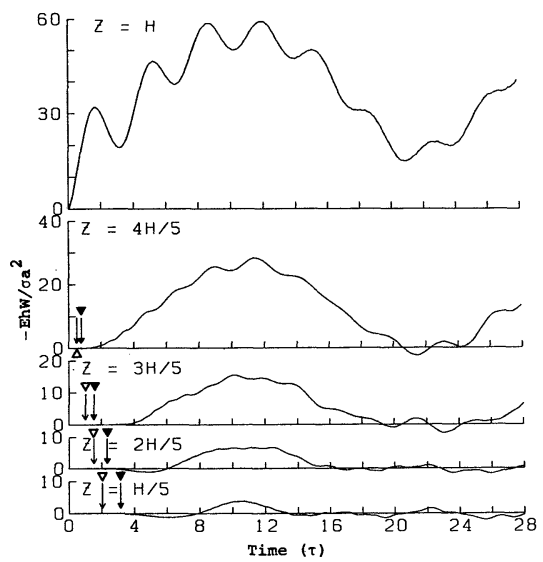

Fig. 9 Transient responses of normal displacement for hyperboloidal shell.

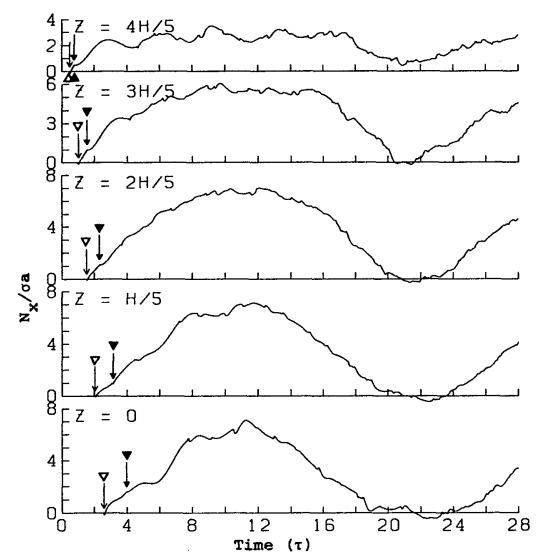

Fig. 10 Transient responses of meridional stress resultant for hyperboloidal shell.

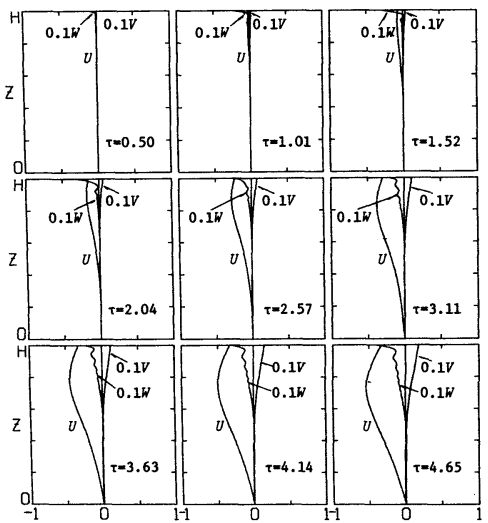

Fig. 11 Deformation profiles $\left(E h U / \sigma a^{2}, E h V / \sigma a^{2}, E h W /\right.$ $\left.\sigma a^{2}\right)$ at various time points for hyperboloidal shell.

0.0014 とした $\left(S_{\min }=0.1668\right)$.

Fig. 9 と 10 に，固定端から回転軸に沿って測った着 目点 $Z$ における変位 $W$ と合応力 $N_{x}$ の時間応答を示 す.図には，荷重点から発した縦波とせん断波が最初に

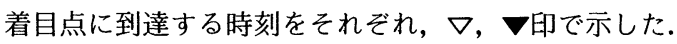
得られた結果は，理論解が求められていないので正確な 精度の評価はできないが, 応答の立ち上がりなどは応力 波の伝播現象をほぼ表わしている.

Fig. 11 は, 自由端から伝播した縦波が固定端に到着・ 反射 $(\tau=2.57) し ，$ スロート部に至る $(\tau=4.65)$ 時 間帯での回転軸に沿う変形分布の推移を示したものであ る.図は，伝播速度の最も早い応力波である縦波の速度 で変形 $U$ が先行し, その後をせん断波の速度で変位 $V$ と $W$ が推移していく様子をほぼとらえている.

ここでは, 基本的な形状の回転殻についてのみ数值例 を示したが，本論文の目的の 1 つである選点法の応力波 伝播の問題に対する適用可能性と妥当性に関しては, （1）と（2）の数值例を通して確認できたものと思わ れる.

\section{5. おわりに}

本論文は，回転殻の応力波伝播の問題について，空間 領域に対する選点法の適用性, 有効性の検討を行ったも のである.その際，選点法の適用により得られた時間に 関する 2 階連立微分方程式に対し，陽および陰な直接時 間積分公式を用いて構成した，2 種の計算アルゴリズム を提示した。ここで得られた成果を要約すれば次のよう になる.

（1）選点法と陽解法の組合せの場合には，両手法の 特性が生かされて, 比較的次数の低い行列演算よりなる 計算アルゴリズムが必然的に得られた。 また，中心差分 法を用いるときの時間間隔に関する安定限界と選点法に 
基づいて定式化された固有値問題の関連を明確にした。

（2）選点法と陰解法の組合せの場合には，FEM で 知られている部分構造法に類似な手法を導入することに より, 大次元な行列演算を回避できる計算アルゴリズム となった.

（3）回転殼修正理論式の選点法による空間領域の近 似の仕方は, 一要素内の選点数 $M$ には 11 程度を選び, 要求される精度に呼応して要素分割数 $N$ を増すことが 適切である.

（4）数値例として, 円筒壳と双曲殼の波動伝播問題 の解析例を示した.いずれもほぼ十分な精度の解が得ら れており, 選点法の有効性が確認できた。

本研究は選点法の空間領域に対する適用性, 有効性に 限定して検討したが, 今後は, ここで用いた時間積分ス キームや他の積分スキームの組合せによる多数の解析を 実施し, 精度と効率の検討を行うとともに, せん断変形 と回転慣性の応力波伝播問題に及ぼす影響を定量的に明 らかにする予定である.

なお, 数值計算には, 北海道大学大型計算機センター の HITAC M-280 H を用いたことを付記する.

\section{付録 I}

行列 $\boldsymbol{C}, \boldsymbol{D}, \boldsymbol{E}, \boldsymbol{G}$ および $\boldsymbol{H}$ の非零成分は次のように なる.

$$
\begin{aligned}
& c_{11}= \rho_{1} / s^{2}, \quad c_{22}=\nu_{1} c_{11}, \quad c_{33}=\nu_{1} x c_{11} \\
& c_{44}=\delta / s^{2}, \quad c_{55}=\nu_{1} c_{44} \\
& c_{14}=c_{41}=-\delta\left(r_{1}-r_{2}\right) / s^{2} \\
& c_{25}=c_{52}=\nu_{1} c_{14} \\
& d_{11}=\rho_{4} / s^{2}, \quad d_{12}=-d_{21}=n \nu_{2} / s r \\
& d_{13}=-d_{31}=\left(\nu r_{2}+\rho_{1} \rho_{3} r_{1}\right) / s \\
& d_{14}=-d_{41}=-\delta r_{1}^{\prime} / s^{2}, \quad d_{22}=\nu_{1} d_{11} \\
& d_{33}=\nu_{1} x d_{11}, \quad d_{44}=\gamma \delta / s^{2}, d_{55}=\nu_{1} d_{44} \\
&\left.d_{34}=-d_{43}=\mid \delta\left(r_{1}-r_{2}\right) r_{1}+\nu_{1} x \rho_{1}\right\} / s \\
& d_{25}=d_{52}=-\nu_{1} \delta r_{1}^{\prime} / s^{2}, d_{45}=-d_{54}=n \delta \nu_{2} / s r \\
& e_{11}=-\nu r_{1} r_{2}-\rho_{2} \rho_{6} \\
& e_{22}=\nu_{1} r_{1} r_{2}-\rho_{2}\left(\rho_{5}+\nu_{1} x r_{2}^{2}\right) \\
& e_{33}=-\nu_{1} n^{2} x \rho_{2} / r^{2}-\left\{r_{1}^{2}+r_{2}^{2}+2 \nu r_{1} r_{2}\right. \\
&\left.\quad+\delta\left(r_{1}-r_{2}\right)\left(r_{1}^{3}-r_{2}^{3}\right)\right\} \\
& e_{44}=-\delta\left(\nu r_{1} r_{2}+\rho_{6}\right)-\nu_{1} x \rho_{1} \\
& e_{55}=\delta\left(\nu r_{1} r_{2}-\rho_{5}\right)-\nu_{1} x \rho_{2} \\
& e_{12}=e_{21}=-n \gamma \nu_{3} \rho_{2} / s r \\
& e_{13}=\left\{r_{1}^{\prime} \rho_{7}+\gamma\left(r_{1}-r_{2}\right)\left(1+\delta r_{2}^{2}\right)\right\} / s \\
& e_{31}=\left\{\nu_{1} x r_{1}^{\prime} \rho_{7}-\gamma\left(\nu_{1} x r_{1}+\nu r_{1}+r_{2} \rho_{2}\right)\right\} / s \\
& e_{14}=e_{41}=-\delta\left(r_{1}-r_{2}\right) \rho_{6}+\nu_{1} x \rho_{1} r_{1} \\
& e_{15}=e_{51}=-n \gamma \delta\left(r_{1}-r_{2}\right) \nu_{3} / s r \\
& e_{23}=e_{32}=-n\left(\nu r_{1}+r_{2} \rho_{2} \rho_{3}\right) / r \\
& e_{24}=e_{42}=e_{15}
\end{aligned}
$$

$$
\begin{aligned}
& e_{25}=e_{52}=-\delta\left(r_{1}-r_{2}\right) \rho_{5}+\nu_{1} x \rho_{2} \nu_{2} \\
& e_{34}=e_{43}=\nu_{1} x \rho_{4} / s-\delta \gamma r_{2}\left(r_{1}-r_{2}\right) / s \\
& e_{35}=e_{53}=n\left\{x \nu_{1}-\delta\left(r_{1}-r_{2}\right) r_{2} \rho_{3}\right\} / r \\
& e_{45}=e_{54}=-n \delta \gamma \nu_{3} / s r \\
& g_{11}=b \rho_{1} / s, \quad g_{14}=-b \delta\left(r_{1}-r_{2}\right) / s, \quad g_{22}=\nu_{1} g_{11} \\
& g_{25}=\nu_{1} g_{14}, \quad g_{31}=g_{14}, \quad g_{34}=b \delta / s \\
& g_{42}=\nu_{1} g_{14}, \quad g_{45}=\nu_{1} g_{34}, \quad g_{53}=b \nu_{1} x \rho_{1} / s \\
& h_{11}=b \nu \gamma / s, \quad h_{12}=b \nu n / r, \quad h_{21}=-b \nu_{1} n / r \\
& h_{13}=b\left(r_{1} \rho_{1}+\nu r_{2}\right), \quad h_{22}=-b \nu_{1} \gamma / s \\
& h_{33}=-b \delta\left(r_{1}-r_{2}\right) r_{1}, \quad h_{34}=b \delta \nu \gamma / s \\
& h_{35}=b \delta \nu n / r, \quad h_{44}=-b \nu_{1} \delta n / r \\
& h_{45}=-b \nu_{1} \delta \gamma / s, \quad h_{51}=-b \nu_{1} x \rho_{1} r_{1} \\
& h_{54}=b \nu_{1} x \rho_{1} \\
& 己 こ に, \\
& \rho_{1}=1+\delta\left(r_{1}-r_{2}\right) r_{1}, \quad \rho_{2}=1-\delta\left(r_{1}-r_{2}\right) r_{2} \\
& \rho_{3}=1+\nu_{1} x, \quad \rho_{4}=\gamma+\delta r_{1}^{\prime}\left(2 r_{1}-r_{2}\right) \\
& \rho_{5}=\nu_{1} \gamma^{2} / s^{2}+n^{2} / r^{2}, \quad \rho_{6}=\gamma^{2} / s^{2}+\nu_{1} n^{2} / r^{2} \\
& \rho_{7}=1+\delta\left(3 r_{1}-2 r_{2}\right) r_{1}, \quad \nu_{1}=(1-\nu) / 2 \\
& \nu_{2}=(1+\nu) / 2, \quad \nu_{3}=(3-\nu) / 2 \\
& b=1 /\left(1-\nu^{2}\right)
\end{aligned}
$$

\section{付録 II}

$\boldsymbol{\alpha}_{c}^{(k)}$ および $\boldsymbol{\alpha}_{e}^{(k)}$ の具体的内容は以下のようになる. た とえば, 式（9）の $u$ に関する式から得られる成分は 次のようである.ただし, 記述を簡単にするため式 (9) の係数は定数とする.

$$
\begin{aligned}
& \alpha_{c}^{(k)} \text { について } \\
& \begin{aligned}
\alpha_{c}^{(k)}(i, j)= & c_{11} B(i+1, j+1)+d_{11} A(i+1, j+1) \\
& +e_{11} \delta_{i j} \\
\alpha_{c}^{(k)}(i, M+j)= & d_{12} A(i+1, j+1)+e_{12} \delta_{i j} \\
\alpha_{c}^{(k)}(i, 2 M+j)= & d_{13} A(i+1, j+1)+e_{13} \delta_{i j} \\
\alpha_{c}^{(k)}(i, 3 M+j)= & c_{14} B(i+1, j+1)+d_{14} A(i+1, j+1) \\
& +e_{14} \delta_{i j} \\
\alpha_{c}^{(k)}(i, 4 M+j)= & e_{15} \delta_{i j}
\end{aligned}
\end{aligned}
$$

ただし， $i, j=1 \sim M, \delta_{i j}$ は Kronecker のデル夕記号で あり, $A(i+1, j+1)$ および $B(i+1, j+1)$ は式 (13) の行列 $\boldsymbol{A}$ および $\boldsymbol{B}$ の成分を表わす.

$$
\begin{aligned}
& \boldsymbol{\alpha}_{e}^{(k)} \text { について; } \\
& \alpha_{e}^{(k)}(i, 8+j)=0 \\
& \text { うものとする. } \\
& l \begin{cases}=1 & ; j=1 \\
=M+2 & ; j=2\end{cases}
\end{aligned}
$$$$
\alpha_{e}^{(k)}(i, j)=c_{11} B(i+1, l)+d_{11} A(i+1, l)
$$$$
\alpha_{e}^{(k)}(i, 2+j)=d_{12} A(i+1, l)
$$$$
\alpha_{e}^{(k)}(i, 4+j)=d_{13} A(i+1, l)
$$$$
\alpha_{e}^{(k)}(i, 6+j)=c_{14} B(i+1, l)+d_{14} A(i+1, l)
$$$$
\text { ただし， } i=1 \sim M, j=1,2 \text { であり, } l \text { は次の約束に従 }
$$ 
参考 文 献

1）たとえば，日本機械学会・衝撃と破壊調査研究分科会： 文献目録集，1981（1965１978 の間の国内外の衝撃関係 文献約 4200 の分類収録).

2) 三上 隆：空間領域に選点法を用いた回転壳の静的およ び動的問題の解析, 土木学会論文報告集, 第 341 号, pp. $69 \sim 78,1984$.

3) Magrab, E. B. : Vibrations of Elastic Structural Members, Sijthoff \& Noordhoff, 1979.

4) Houbolt, J.C. : A recurrence matrix solution for the dynamic response of Elastic aircraft, J. Aeronaut. Sco., Vol. 17, pp. 540 550, 1950.

5) Hildebrand, F. : Finite Difference Equations and Simulations, Prentice-Hall, Englewood Cliffs, 1968.

6) Leech, J. W. et al. : Stability of finite difference method for solving matrix equation, AIAA. J., Vol. 3, No.11, pp. 2172 2173, 1965.

7）三上 隆・芳村 仁：選点法による回転壳の固有振動数 の解析, 土木学会論文報告集, 第 335 号, pp. $69 \sim 78$, 1983.

8) Reismann, H. and Modige, J. : Forced motion of cylindrical shell, Proc. of ASCE, Vol.94, No. EM 5, pp. 1167 1182, 1968.

9) Reismann, H. and Weingarten, L. I. : Forced motion of cylindrical shells_A comparison of shell with elasticity theory, Z. A. M. M., Vol.54, pp. 181 191, 1974.

10) Odaka, T. and Nakahara, I. : Stress in an infinite beam impacted by an elastic bar, Vol.10, No.42, pp.863 872, 1967.

(1985.4.1 - 受付) 